\title{
Research Prospect of Intelligent Technology of Ship Coating Process
}

\author{
Chao XU, Hong ZHOU, Jianfeng LIU
}

\begin{abstract}
Ship painting is an important part of ship construction process. From the initial painting design to the actual application of painting equipment and production management of painting operation, it contains various information such as paint, painting equipment, working hours quota, operation cycle, production management, etc. Under the rapid development of modern information technology, with the application of data analysis technology and the research object of typical coating intelligent equipment and coating production management, the paper establishes the data output interface of coating design and coating intelligent equipment and coating production management process characteristics, and compiles the coating intelligent design technical specifications for intelligent equipment and coating intelligent design technology for coating production management Standard of operation. Based on the 3D model of single data source, the standard of coating engineering definition, intelligent decomposition of coating engineering, coating process information and coating intelligent equipment information are used to develop the integrity characteristic standard of coating 3D model. Analyze and evaluate the auxiliary software of coating design, and carry out the secondary development of coating intelligent software according to the evaluation effect. Based on the analysis of 3D modeling information, production management information and typical coating equipment information in the existing ship coating design process, this paper makes a plan to realize the transformation from traditional coating process design technology to intelligent design in the future and form a complete coating process intelligent design system.
\end{abstract}

Index Terms - Ship Painting Design, Production Management, Intellectualization..

\section{INTRODUCTION}

The development of the intelligent design technology of the coating process is the only way to the future development of the ship. The study required for this process involves all aspects of shipbuilding. In the course of the future research, a great deal of research needs to be done. And the future development of the coating intelligent technology is predicted in combination with its own research experience.

\section{RESEARCH ON THE DEFINITION OF THE DESIGN OF THE INTELLIGENT MANUFACTURING AND PAINTING}

In order to realize the intelligent painting design technology driven by big data, the standardized coating design engineering definition and the intelligent decomposition technology of coating engineering are carried

Chao Xu, School of Naval Architecture \& Ocean Engineering, Jiangsu University of Science and Technology, Zhenjiang, Jiangsu, China

Hong Zhou, Professor, School of Naval Architecture \& Ocean Engineering, Jiangsu University of Science and Technology, Zhenjiang, Jiangsu, China

Jianfeng Liu, chief technologist of Waigaoqiao shipyard, Shanghai, China out, which lays the foundation for the final realization of intelligent drawing of coating process design[1].

A. Research on definition of coating Engineering for Intelligent Manufacturing

The standardized definition of painting process related information is carried out, including ship position definition, area definition, cabin definition, component definition, operation stage definition, material quantity definition, rust removal mode and grade definition, coating matching definition, material and man-hour quota definition, testing equipment definition and so on, which provides support for the establishment of accurate and complete painting process information data source[2].

\section{B. Research on the Technology of Intelligent Decomposition of the Coating Engineering for Shell-and-Tube-coating}

The coating operation stage shall be refined according to the process of ship construction based on the standardized definition of coating engineering. And decomposing according to the space element. In combination with the work of processing, assembling and assembling, it is necessary to form an integrated coating job decomposition standard facing the shell and to form the intelligent decomposition technology on the basis of this.

\section{Study on the Application of Engineering definition of Regional painting}

Based on the complexity of coating process and the requirement of high complexity of coating, the typical segment based on the complexity of coating process and the requirement of intelligent spraying are selected to complete the verification and evaluation of design application by using the intelligent auxiliary design system of coating[3].

The existing 3-dimensional modeling software for painting is shown in Figure 1.1 below. The model information contained in the model is more, and the information irrelevant to the coating can be eliminated, so that the light weight of the model can be derived.

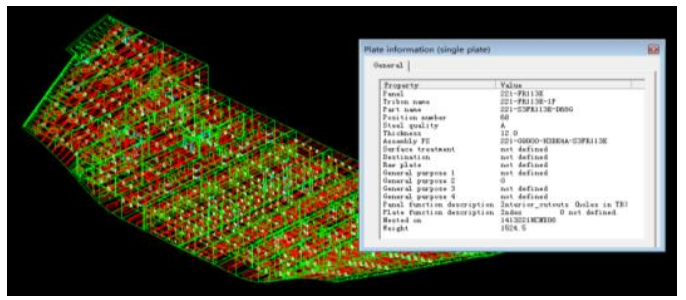

Fig1.1 3D model information

\section{RESEARCH ON INTELLIGENT DESIGN OF COATING FOR EQUIPMENT AND MANAGEMENT}

In order to realize the connection between the intelligent design and the equipment and management of the coating process, a research on the application of intelligent design 
technology, which is based on the information of typical robot and coating production management, is carried out, and a comprehensive technical study on the intelligent design of coating based on a single data source is carried out.

A. Research on Intelligent coating process characteristics for equipment and Management

The equipment and management information related to the coating process is sorted, the data logic of the relevant information and the coating process information is established, the data structure is unified, and the general expression of the process characteristics is realized.

\section{B. Research on Intelligent Design of Coating for Typical Robot}

Taking the typical painting robot as the research object, the geometric information, spatial information, process information and other related process characteristics are systematically analyzed, and the data interface with the definition of painting design engineering is established. Combined with the process decomposition technology, the connection between coating design data and intelligent equipment is realized.

\section{Research on Intelligent painting Design Technology for production Management Informatization}

Based on the standardization definition of the coating design project, the coating process data (derusting method and grade, coating grade and name, coating process, etc.) and production management information (coating operation environment management, coating quality management, coating film thickness management, engineering plan management, etc.) are established. The logical relation of coating material management, coating working hour management, coating safety management, etc.) is used to form the data interface, and the connection between the application intelligent design technology and the production management information is realized. The existing coating production management system is shown in Figure 2.1 below.

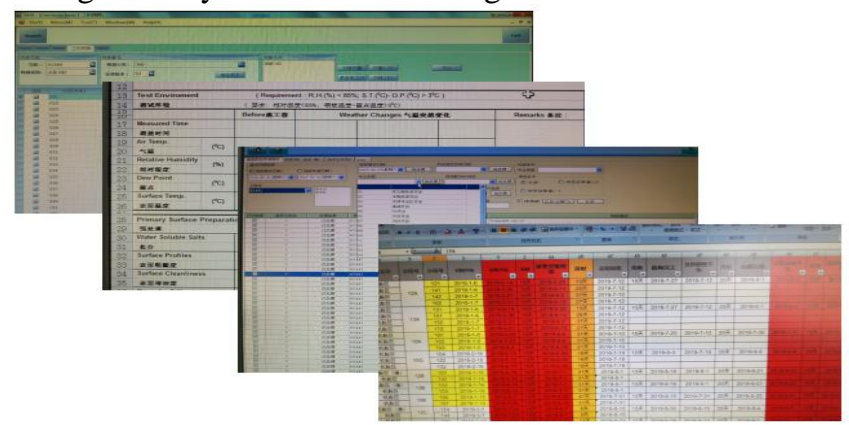

Fig 2.1 Coating Production Management Interface

\section{Research on Intelligent Design Technology of painting} based on single data Source

Based on the single data source of three-dimensional model, the coating intelligent design technology based on single data source is established by using the painting intelligent design technology of typical robot and the painting intelligent design technology of coating production management information, and the comprehensive technology of painting intelligent design based on single data source is established through data integration.

\section{RESEARCH ON APPLICATION TECHNOLOGY OF INTELLIGENT PAINTING DESIGN}

The coating design covers a large amount of data information such as the paint supplier, the series of products, the technical parameters of the products, the coating construction process and the like. The process design of coating process also has the characteristics of complexity, multi-factor and experience. Under the background of different design software, the integrity modeling of the coating process is realized to solve the problem of the extraction, transmission and exchange of data instructions between the coating management system and the intelligent spraying equipment by the surface space position information, the geometric information and the process information of the coating structure.

A. Study on the Integrity of the Three-dimensional Model for the Intelligent Design of the Coating

Based on the three-dimensional model, the painting design, production, management and other information are combed, the relevant digital standards are established, and the complete product digital definition information is integrated with a single data source.

B. Research on the Technology of the Design of the Application of the Design Tools for the Application of the Intelligent Design

According to the requirement of $3 \mathrm{D}$ model integrity feature of painting intelligent design, the auxiliary development of design tool is carried out, and the intelligent extraction technology is formed to realize the accuracy and integrity of painting intelligent design.

C. Application of Intelligent painting Design based on typical Segmentation

A typical section based on the requirements of coating process and matching complexity is selected, and the design application verification and evaluation are completed by applying the intelligent design system of coating intelligent design for the process requirements of the intelligent spraying equipment.

\section{SUMMARY}

The application of intelligent technology is the inevitable development trend of all kinds of businesses in the future, and the painting in the shipbuilding industry will inevitably progress with the development of the times. The intelligence of painting design, production and management will greatly improve the efficiency of ship painting operation and make the development of the shipbuilding industry enter a new stage.

\section{REFERENCES}

[1] LV Delong. No delay! Intelligent manufacturing is on the way [J] Guangdong shipbuilding, 2017, (3): 4-7

[2] Peng Juan. Analysis of ship painting design system based on Intelligent Technology [J]. Automation application, 2017 (01): 26-28

[3] Wang Guoping. Basic knowledge of ship painting (5) design of ship painting ( II ) [J]. Coating industry, 1991 (01): 49-51

Chao Xu, School of Naval Architecture \& Ocean Engineering, Jiangsu University of Science and Technology, Zhenjiang, Jiangsu, China

Hong Zhou, Professor, School of Naval Architecture \& Ocean Engineering, Jiangsu University of Science and Technology, Zhenjiang, Jiangsu, China

Jianfeng Liu, chief technologist of Waigaoqiao shipyard, Shanghai, China 